\title{
A community based study on finding the Quality of Life of the patients with Vitiligo
}

\author{
Dilshad Ahmad* \\ College of Pharmacy, King Saud Bin Abdul Aziz University for Health Sciences, Riyadh, Saudi Arabia.
}

\begin{tabular}{l} 
ARTICLE INFO \\
\hline Article history: \\
Received on: $10 / 01 / 2017$ \\
Accepted on: $20 / 03 / 2017$ \\
Available online: $30 / 05 / 2017$ \\
\hline Key words: \\
Vitiligo, mental stigma, \\
Quality of life, DLQI, Unani \\
Medicine.
\end{tabular}

\section{E INFO}

\begin{abstract}
Vitiligo is a skin related disease and caused by the loss of skin color in blotches. It is a worldwide problem. By the treatment of vitiligo has improve the appearance of the affected skin of a person but there is no permanent cure treatment available for this disease. Data were collected from the individuals with Vitiligo who were under treatment in Dermatology clinic and were included in this study. A total of 200 individuals agreed to participate. Data were collected in the year of 2014 through a well-defined questionnaires and clinical examinations. We have carried out a detailed psychological analyses based on the response to queries. Patients with vitiligo averaged age was $32.4 \pm 13.9$ years. The maximum disability of the affected persons were measured by the DLQI summary score. Disability in patients was highest in treatment category with $54.71 \%$ of impairment followed by symptoms and feelings, with $41.48 \%$. The present study has revealed that the association of Vitiligo with impairment in different aspects of life. Finally, the study showed that in the vitiligo patients' quality of life are poor and it is directly associated with their social life. So, the quality of life to be improve is becoming a difficult task. From this study we understood the importance of DLQI sheet in designing and evaluation of efficacy of treatment on Vitiligo patients.
\end{abstract}

\section{INTRODUCTION}

Vitiligo is a pigmentation disorder in which malonocytes in the skin are destroyed. It is great concern of stigma due to white patches on different parts of the body, including face, hand and retina. Nearly one hundred million people suffering from vitiligo worldwide (Ortonne, 1993; Handa and Dogra, 2003). People with Vitiligo can experience emotional stress. More than a skin disorder, it is a cause of psychological and mental stigma. Dating from a remote period and onwards, the vitiligo patients affected by the mental worries as the leprosy patients. The stigma is more at early stage in India, as young women with vitiligo has little chance of getting married, because of various superstitions that go with the disease apart from the

\footnotetext{
* Corresponding Author

Email: ahmadd@ksau-hs.edu.sa
}

physical aspect and sexual activity (Porter and Beuf.,1991). It is therefore significant to analyze the levels of psychological stress of patients from different social mindsets as an important indicator on the quality of life. The appearance of Vitiligo patient's skin can state an individual's self-image, and any pathological alteration can have psychological consequences as well (Le poole, 1997).

This disease is majorly classified based upon its distribution, pattern and its magnitude of the depigmentation. Many papers and results were available on its classifications. The most researchers classified into a two major subtypes of vitiligo like segmental vitiligo (SV) and non-segmental vitiligo (NSV) (Taieb, 2000). This analysis describes self - reported DQOL of patients with segmental and non-segmental vitiligo. The main concentration of our present study was to investigate the dermatology quality of life and psychological impact with frequency, severity and diversity of Vitiligo patients among ethnic population. 


\section{MATERIALS AND METHODS}

In this community based study 200 persons data were included by face to face survey using pre - structured questionnaire in the Tamil State, India in early 90s and dropped the idea due to some reason and then again surveyed in January to March 2014. Out of 200 persons 155 were underwent the treatment for Vitiligo in Dermatology clinic and those who were completed the questionnaire related to Dermatology Life Quality Index -DLQI (Finlay and Khan., 1994) were included in the data analysis. The response rate of this study was $77.5 \%$. Study participants were $>16$ years of age, of either gender and with both types of Vitiligo. Patients with age of $\leq 16$, having any other diseases and those who left any question unanswered were not included in the analysis. Data were entered in the Micro Soft Excel 2010 and analyzed by SPSS 21.0 Version software. Data were expressed as descriptive statistics and proportion of the impairment for the both total and subgroups.

\section{DLQI}

DLQI was measured in the following method:

(1) DLQI measures by the six -specific domains, like symptoms and feelings, leisure activities, day activities, work and school, personal relationships and treatment. (2) 4-point scale. Zero was taken as not at all, and 3 considered high. (3) Overall total of individual items are taken as QOL score. These scores are mentioned as proportions, in that the higher scores were taken as greater impairment and recall history period of those were affected by this disease was considered for the last 7 days.

\section{RESULTS}

Out of 155 patients, $88(56.8 \%)$ were males and 67 (43.2\%) females. Among 155 patients 41 (26.5\%) were segmental and $114(73.5 \%)$ were under non - segmental group. The socioeconomic demographic variables are very clearly shown in Table - $\mathbf{1}$ and the DLQI \% scores were shown clearly in Figure - 1. By using the DLQI summary scores, the patients with vitiligo averaged age was found as $32.4 \pm 13.9$ years. The disability of the Vitiligo patients were showed in the treatment component of the DLQI. It measures pain, stress and difficulties faced in getting the right kind of treatment, with $56.1 \%$ of impairment reported. This was followed by symptoms and feelings, with $41.9 \%$ of impairment measuring the embarrassment and suffering associated with the disease. The impairment in occupation and institutions and leisure activities were lying from $9.7 \%$ to $16.8 \%$ respectively and were shown in Table - 2. The overall patients disability in their daily activities due to Vitiligo was found in male and female were $29.4 \%$ and $29.6 \%$ respectively.

The total score of segmental was almost same as that of non-segmental $(26.8 \%$ vs $28.1 \%)$. Patients with non-segmental type continuously scored higher in the components of DLQI except the comparison of personal relationship to segmental type. Comparison of non-segmental patients with segmental patients were younger age $(30.2 \pm 13.2$ vs. $33.3 \pm 14.2)$ years, more likely males being affected than females $(63.4 \%$ vs $54.4 \%$ and $36.6 \%$ vs $45.6 \%$ ).

Dark skinned individuals with vitiligo had maximum total impairment of $31.3 \%$ when compared to other group. Consanguineously married patients showed least impairment in all components of DLQI when compared to no consanguineous couples. Unmarried Patients showed greater impairment in symptoms and feeling and leisure component of DLQI when compared to married patients. Patients with duration of disease between 6 - 10 years averaged $29.6 \%$ of maximum disability which is higher (worse) than those below 6 years $27.1 \%$ and also had the maximum score in treatment component $76.5 \%$. Slow responders showed greater impairment in treatment section of DLQI $62.3 \%$ compared to rapid responders $26.2 \%$.

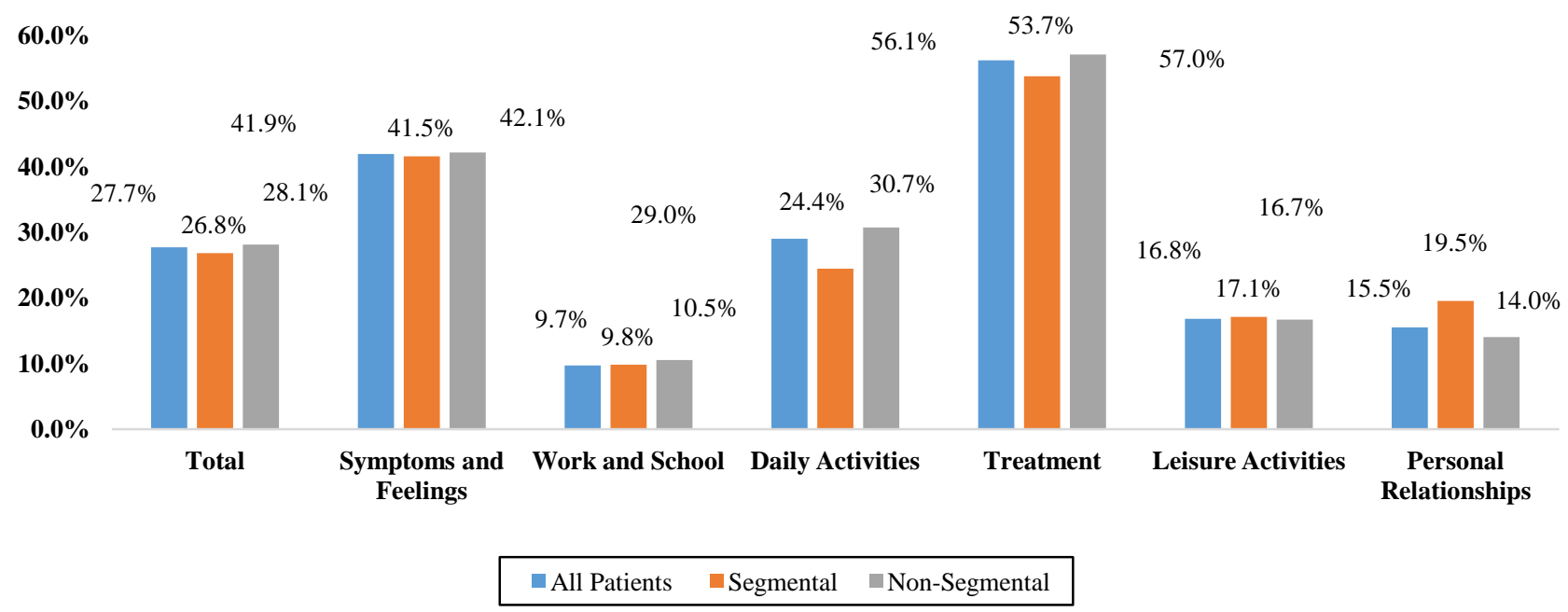

Fig. 1: Distribution of Quality of life; Percentage impairment in the Dermatological Quality of Life 
Table 1: Distribution of baseline demographic variables of Vitiligo Patients.

\begin{tabular}{|c|c|c|c|c|}
\hline \multirow{2}{*}{\multicolumn{2}{|c|}{ Variables }} & \multicolumn{3}{|c|}{ ANALYSIS GROUP } \\
\hline & & $\begin{array}{l}\text { All Patients } \\
\mathbf{N}(\%)\end{array}$ & Segmental & Non - Segmental \\
\hline Age (in years) & Mean + SD (Ranqe) & $324+139(16-74)$ & $302+132(16-61)$ & $333+142(17-74)$ \\
\hline \multirow{2}{*}{ Gender } & Male (\%) & $88(56.8)$ & $26(63.4)$ & $62(54.4)$ \\
\hline & Female (\%) & $67(43.2)$ & $15(36.6)$ & $52(45.6)$ \\
\hline \multirow{3}{*}{ Skin Color } & Dark & $35(22.6)$ & $9(21.9)$ & $26(22.8)$ \\
\hline & Medium & $92(59.3)$ & $25(60.9)$ & $67(58.8)$ \\
\hline & Fair & $28(18.1)$ & $7(17.1)$ & $21(18.4)$ \\
\hline \multirow{2}{*}{ Marital Status } & Married & $82(52.9)$ & $19(46.3)$ & $64(56.1)$ \\
\hline & Un- married & $73(47.1)$ & $23(56.1)$ & $50(43.9)$ \\
\hline \multirow{2}{*}{ Treatment } & With Treatment & $143(92.3)$ & $39(95.1)$ & $104(91.2)$ \\
\hline & Without Treatment & $12(7.7)$ & $2(4.88)$ & $10(8.8)$ \\
\hline \multirow{2}{*}{ Duration of disease } & $\leq 10$ & $146(94.2)$ & $40(97.6)$ & 106 (92.9) \\
\hline & $>10$ & $9(5.8)$ & $1(2.4)$ & $8(7.0)$ \\
\hline
\end{tabular}

Table 2: Percentage of QOL of Sub Groups and impairment in the Dermatological Quality of Life (DQoL) of various sub groups of Vitiligo Patients.

\begin{tabular}{|c|c|c|c|c|c|c|c|c|c|}
\hline \multicolumn{3}{|c|}{ DLQI (\%) } & Total & $\begin{array}{c}\begin{array}{c}\text { Symptoms \& } \\
\text { feelings }\end{array} \\
\end{array}$ & Daily activities & Leisure & $\begin{array}{c}\text { Work \& } \\
\text { study }\end{array}$ & $\begin{array}{c}\text { Personal } \\
\text { relationships }\end{array}$ & Treatment \\
\hline \multirow{2}{*}{ Gender } & \multicolumn{2}{|c|}{ Male } & 27.5 & 39.8 & 29.4 & 17 & 12.1 & 17.8 & 55.3 \\
\hline & \multicolumn{2}{|c|}{ Female } & 27.1 & 44.5 & 29.6 & 16.7 & 6.9 & 12.7 & 57.2 \\
\hline \multirow{4}{*}{$\begin{array}{l}\text { Duration of } \\
\text { disease }\end{array}$} & \multicolumn{2}{|c|}{$1-5 \mathrm{yrs}$} & 27.1 & 47.1 & 29.5 & 17.2 & 9.8 & 15.6 & 52.2 \\
\hline & \multicolumn{2}{|c|}{$6-10 \mathrm{yrs}$} & 29.6 & 35.3 & 36.3 & 13.7 & 11.8 & 18.7 & 76.5 \\
\hline & \multicolumn{2}{|c|}{$>10 y r s$} & 27 & 50 & 16.7 & 18.5 & 7.7 & 9.3 & 74 \\
\hline & \multicolumn{2}{|c|}{ New cases } & 22.6 & 33.3 & 25.9 & 11.1 & 18.5 & 12.9 & 40.8 \\
\hline \multirow{3}{*}{$\begin{array}{l}\text { Response to } \\
\text { Treatment }\end{array}$} & \multicolumn{2}{|c|}{ Without Treatment } & 26.1 & 37.9 & 33.3 & 18.2 & 6.1 & 18.2 & 39.4 \\
\hline & \multirow{2}{*}{$\begin{array}{c}\text { With } \\
\text { Treatment }\end{array}$} & Rapid & 26.2 & 41.7 & 39.3 & 17.9 & 9.5 & 14.3 & 26.2 \\
\hline & & Slow & 27.9 & 42.8 & 28.2 & 17.1 & 9.6 & 15.1 & 62.3 \\
\hline \multirow{3}{*}{ Marital Status } & \multicolumn{2}{|c|}{ Married } & 27.2 & 41.7 & 30.4 & 15.9 & 8.8 & 17.4 & 52.5 \\
\hline & \multicolumn{2}{|c|}{ Unmarried } & 29 & 44.5 & 30.1 & 19.6 & 11.9 & 15.1 & 61.2 \\
\hline & \multicolumn{2}{|c|}{ Consanguineous } & 18.6 & 28.6 & 21.4 & 7.1 & 4.76 & 9.5 & 47.6 \\
\hline \multirow{3}{*}{ Skin Color } & \multicolumn{2}{|c|}{ Dark skin } & 31.3 & 47.1 & 36.2 & 17.6 & 14.3 & 16.2 & 69.8 \\
\hline & \multicolumn{2}{|c|}{ Medium } & 27 & 41.5 & 28.4 & 17.4 & 10.5 & 15 & 54.7 \\
\hline & \multicolumn{2}{|c|}{ Fair } & 23.6 & 36.3 & 24.4 & 14.3 & 2.4 & 16.7 & 50 \\
\hline
\end{tabular}

\section{DISCUSSION}

Vitiligo has a significant psychological impact on all ages caused by depigmentation (Mechri et al., 2006). The possible causes are stress, accumulation of toxic compounds, infections, autoimmunity, mutation, altered cellular environment and impairment can lead to the hypopigmentation and finally affected by vitiligo (Pooja Pahwa et al., 2013). By this, the thick colored skinned with white patches as the contrast between the pigmented and depigmented skin can be vehement. There is a stigma attached to having vitiligo in some other cultures. The persons those who were affected with this are sometimes thought to be evil or affected by a diseases are neglected by others living in the surrounding. Those who were affected by this skin disease may feel depressed because of this affects or because their appearance has changed fully than a normal person and the fact that they are not treated on par with normal individuals (Firooz A et al., 2004). This is even more evident as vitiligo sufferers without skin depigmentation have essentially negligible psychological effects. In this study, patients suffering from vitiligo are broadly classified as segmental and non-segmental on the basis of the pattern and distribution of depigmentation. Data was collected from both these groups of patients and further subdivided on the basis of age, sex, skin color, marital status, treatment and duration of disease. It was observed that vitiligo affects all age groups, with nonsegmental patients having an average onset age a year higher than the segmental ones, but an average upper age limit about 13 years more than the segmental patients. More number of males were found to be prone to the disease compared to females. Interestingly, dark and light skinned individuals were found to be much less likely to suffer with vitiligo compared to individuals with a brownish complexion. On the treatment front, an encouragingly huge section $(92.46 \%)$ of the patients responded to various degrees to the treatment given to them at dermatology clinic and in most cases, the disease was found to limit itself for about 10 years after onset.

In our present study, the DLQI scores were taken as 0 to 22 and average value was found as $8.21 \pm 4.88$, which is comparable with Persian population ranged from 0 to 24 and 7.05 \pm 5.13 (Shahin et al., 2004). The average DLQI score in our present study was higher than that the mean. Finlay and Khan. (1994) have mentioned the similar type of results in their study. In another one study related to the Dermatology Life Quality Index among vitiligo sufferers, Kent and Al-Abadie (1996) have 
mentioned in their study the mean as 4.82 , which is lower than Parsad et al. (2003) has mentioned as mean 10.67. In another one study by Salzer and Schallreuter (1995) have mentioned that $75 \%$ was found their disfigurement moderately or severely intolerable. In case Study in India, it has observed the difficulties faced by Vitiligo patients with those who were having leprosy disease (Weiss et al., 1992). A direct correlation was there in between the stress and the development of vitiligo disease. In another one study by Papadopoulos (1999) and Al-Abadie and Kent (1994) have revealed that the psychological stress increases the levels of neuroendocrine hormones that affects the immune system and alters the level of neuropeptides, these could be initial steps in pathogenesis of Vitiligo. So, we have to find commonly from this present study reported that the mental health of the Vitiligo patients is low and it is directly associated with their quality of life.

\section{CONCLUSION}

The present study revealed that the Vitiligo disease is associated with impairment in a variety of psychological ways, especially in treatment, work, at schools, day to day activities. Moreover, the symptoms of Vitiligo can be painful and embarrassing to them were suffering by this skin disease. Patients with non-segmental type of vitiligo were get more impairment than corresponding subgroups because of irregularly spread depigmented patches on the exposed part of the skin. Hence, to improve of the quality of life of the Vitiligo affected persons are very essential and challenging matter. A combined efforts of researchers, entrepreneurs and nonprofit social organization may play a role to improve quality of life in the vitiligo area. The DQLI sheet of evaluation in the treatment of Vitiligo disease is very useful to evaluate the quality of life in various groups of patients classified based on age, sex, basic skin color and other factors.

\section{ACKNOWLEDGEMENT}

I would like to thank to my friend Dr. Shafi for his valuable support of this work and timely help in completing the work.

\section{Financial support and sponsorship: NIL.}

Conflict of Interests: There are no conflicts of interest.

\section{REFERENCES}

Aghaei S, Sodaifi M, Jafari P, Mazharinia N, Finlay AY. DLQI scores in vitiligo: reliability and validity of the Persian version. BMC Dermatology, 2004; 4: 8.
Al'Abadie MS, Kent GG, Gawkrodger DJ. The relationship between stress and the onset and exacerbation of psoriasis and other skin conditions. Br J Dermatol, 1994; 130 (2): 199 - 203.

Finlay AY, Khan GK: Dermatology Life Quality Index (DLQI): a simple practical measure for routine clinical use. Clin Exp Dermatol, 1994; 19 (3): 210 - 216.

Firooz A, Bouzari N, Fallah N, Ghazisaidi, Firoozabadi MR, Dowlati Y. What patient with vitiligo believe about their condition. Int. J. Dermatol, 2004; 43: 811 - 814.

Handa S, Dogra S. Epidemiology of childhood vitiligo: a study of 625 patients from North India. Ped Dermatol, 2003; 20: 207 - 210.

Kent G, Al-Abadie M. Factor's affecting responses on Dermatology Life Quality Index among vitiligo sufferers. Clin Exp Dermatol, 1996; 21 (5): 330 - 333.

Le Poole C, Boissy RE. Vitiligo. In: ArndtKA, Le BoitPE, RobinsonJK, WintroubBU, eds. Semin Cutan Med Surg, Vol. 16. Philadelphia: WB Saunders Company. 1997;

pp. 3-14

Mechri A, Amri M, Douarika AA, Ali-Hichem BH, Zouari B, Zili J. Psychiatric morbidity and quality of life in Vitiligo: a case controlled study. Tunis Med, 2006; 84 (10): 632 - 635.

Ortonne JP, Bose KS. Where do we stand. Pigment Cell Research, 1993; 6: $61-72$.

Papadopoulos L, Bar R, Legg C. Coping with disfiguring effect of vitiligo: A preliminary investigation into effect of cognitive-behavior therapy. Br.J.Med. Phschol, 1999; 72:385-396.

Pahwa P, Mehta M, Binod KK, SharmaVK, Raman M. The Phsychological impact of vitiligo in Indian patients, 2013; 79 (5): 675 685.

Parsad D, Pandhi R, Dogra S, Kanwar AJ, Kumar B. Dermatology life quality index score in vitiligo and its impact on the treatment outcome. Br J Dermatol. 2003; 148 (2): 373 - 374.

Porter JR, Beuf AH. Racial variation in reaction to physical stigma: a study of degree of disturbance by vitiligo among black and white patients. J Health Soc Behav, 1991; 32:192 - 204.

Salzer BA, Schallreuter KU. Investigations of the personality structure in patients with vitiligo and a possible association with catecholamine metabolism. Dermatology, 1995; 190 (2): 109 - 115.

Taieb A. Intrinsic and extrinsic pathomechanisms in vitiligo. Pigment Cell Res, 2000; 13 (8): 41 - 47.

Weiss MG, Doongaji DR, Siddhartha S, Wypij D, Pathare S, Bhatawdekar M, Bhave A, Sheth A, Fernandes R. The explanatory model interview catalogue (EMIC). Contribution to cross-cultural research methods from a study of leprosy and mental health.

Br J Psychiatry, 1992; 160: 819 - 830.

How to cite this article:

Ahmad D. A community based study on finding the Quality of Life of the patients with Vitiligo. J App Pharm Sci, 2017; 7 (05): 090093. 